\title{
The Mode of Origin and the Vascular Supply of the Adventitious Leaves of Cyclamen.
}

BY

\author{
L. A. BOODLE.
}

With six Figures in the Text.

THE mode of origin of the adventitious leaves which arise near the of Cyclamen ${ }^{1}$ has been studied at various stages of their development, and the evolution of the vascular supply to these adventitious leaves has been traced by means of longitudinal and transverse sections.

The first stage in the formation of an adventitious leaf can be recognized by the appearance of division-walls in a small group of cells belonging to

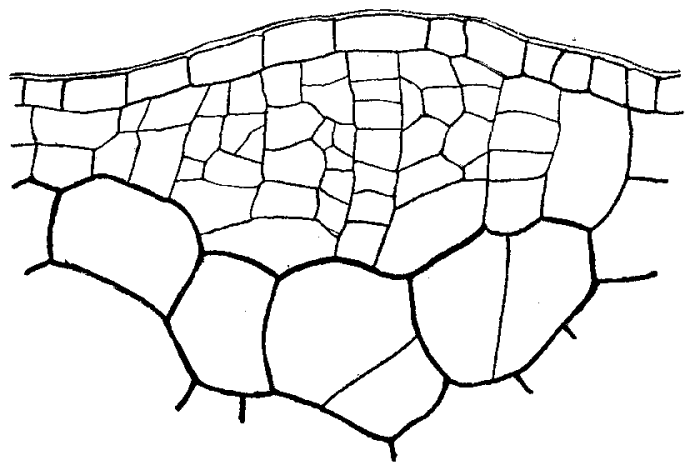

FIa. I. Rudiment of adventitious leaf as seen in a transverse section of the tuber. $\times 25^{\circ}$.

the first layer beneath the epidermis of the young tuber. The first divisionwalls are tangential; and then further subdivision of the cells takes place by means of -walls in different directions. Growth accompanies these divisions, a lenticular mass of small cells being produced (Fig. I). At this stage only a minute external prominence is caused, but the latter increases in size, owing to continued growth and cell-division, and soon, e.g. when $0.2 \mathrm{~mm}$. in length, bears on its surface a number of short glandular hairs, similar to those found on the young cotyledon, tuber, \&c. These hairs being crowded together on the leaf-rudiment, make it easily visible.

1 These leaves mostly grow from the uninjured surface of the tuber, a short distance below the margin of the cut surface.

[Annals of Botany, Vol. XXXIV. No. CXXXVI. October, 1920.] 


\section{Boodle.-The Mode of Origin and the Vascular Supply of}

The tissue produced by division of the sub-epidermal cells gives rise to the internal tissues of the leaf-rudiment, the epidermis of the latter being derived from that of the tuber. The portion of epidermis outside the mass of small cells belonging to the early stage of the leaf-rudiment (see Fig. I), no doubt, stretches slightly at first, and then, as growth beneath it continues, it must undergo rejuvenescence, its cells (or a central group of them) growing and dividing so as to keep pace with the extension of the internal tissues. The original cuticle belonging to this epidermis apparently becomes, exfoliated during the enlargement of the rudiment, pieces of partially detached cuticle having been observed in some cases.

The above description refers to specimens in which no periderm had been produced. Some of the tubers examined, however, were older and had begun to form periderm apparently before the origin of some of the adventitious leaves. One or two early stages of leaf-rudiments were examined, and found to lie immediately beneath the layer of cork-cells, and in lateral contact with the unsuberized layers of the periderm. Later stages showed the cork-layer ruptured, and the young leaf protruding. As the periderm arises in the sub-epidermal layer of the tuber, the epidermis of the leaf, in the cases under consideration, is consequently not derived from that of the tuber, but, together with the inner tissues of the leaf, from portions of the cells of the sub-epidermal layer, or from products of the phellogen.

Thus, taking the cases of the young and older specimens together, it appears that the internal tissues of the leaf are derived from the subepidermal layer of the tuber, either directly or indirectly, but that the epidermis of the leaf may have either an epidermal or sub-epidermal origin.

At the stage of the leaf-rudiment shown in Fig. I, no procambial strand has been formed, but the appearance of a procambial connexion with the stele of the tuber is not long delayed. In Fig. 2 a rudiment of a leaf about $0.5 \mathrm{~mm}$. in length is seen to be connected with the central cylinder by a procambial leaf-trace. The formation of the procambial tissue progresses from without inwards, i. e. from the leaf-rudiment towards the stele, and the progress is presumably rapid, only a few examples of traces stopping short of the vascular ring having been observed. One of the traces referred to reached the endodermis, and one died out half-way across the cortex.

The cells of the procambial trace are formed by repeated divisions in the rather large parenchymatous cells of the cortex of the tuber. A transversely cut procambial trace (perhaps not yet complete), shown in Fig. 3, is seen to have arisen by the subdivision of a single cell, at the level of the section figured. A portion of another trace cut longitudinally is represented in Fig. 4, in which the appearance is suggestive of ordinary cambial divisions. 
Comparison with the preceding figure, however, makes it clear that the narrow cells of Fig. 4 are also shallow, and belong to a bundle of rod-shaped cells, traversing the original large parenchyma-cell from which they have been cut out.

The procambial tissue supplying a single leaf-rudiment becomes connected with two (Fig. 2) or sometimes with three bundles of the vascular ring, and somewhat later develops into vascular tissue. The elements of the latter are short, their length being usually about the same as the diameter of the cells from which they were originally cut out. The phloem-elements remain narrow, but the xylem consists of vessels and tracheides of greater diameter, the segments or elements being often rather broad in proportion to their length, and occasionally isodiametric.

One case was noted in which a leaf-trace had not completed its xylem connexion with the vascular ring, vessels being present only for a certain

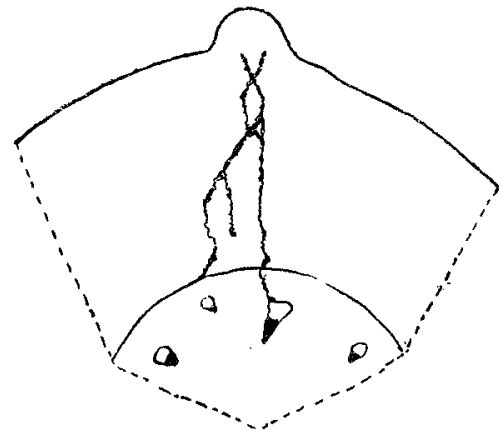

FIG, 2 .

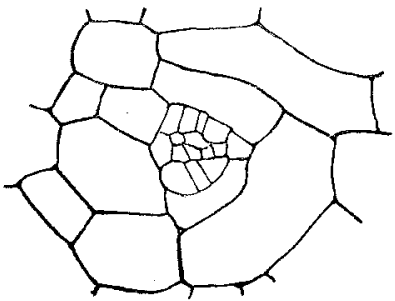

FIG, 3 .

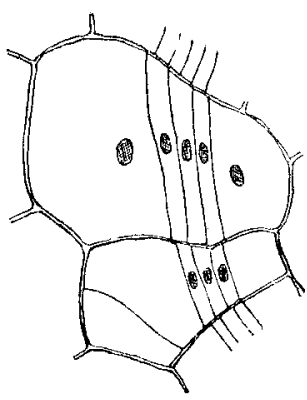

FIG. 4 .

FIgs. 2-4. 2. Portion of transverse section of tuber, showing procambial trace of young adventitious leaf. Some parts of the trace are missing, being outside the thickness of the section. $x 20$. 3. Transversely cut procambial strand of trace of adventitious leaf. $\times 260.4$. Longitudinal section through a portion of a similar trace. $\times 260$.

distance from the leaf-rudiment towards the stele. The differentiation of the xylem of the leaf-trace may therefore begin at the periphery of the tuber and proceed inwards, or perhaps it may commonly begin simultaneously along the whole course of the trace, the instance noted above being an exception.

A vascular connexion between leaf and stele is shown somewhat diagrammatically in Fig. 5. Some portions of the leaf-trace are missing, though a rather thick section was used so as to include the greater part of the connexion. The leaf-trace may exhibit considerable irregularities, including division into two or more strands, and re-fusion of these, during its course, but, speaking generally, it passes inwards in relation to a radial plane and with a slightly downward inclination.

The vessels and tracheides of the leaf-trace usually show either reticulate thickening or scalariform or ordinary pitting, only a few cases in 


\section{Boodle.-The Mode of Origin and the Vascular Supply of}

which spiral thickening was present having been observed. The end-walls of the segments of the vessels have each a simple perforation, which is often small, and may not be recognizable in an optical longitudinal section of a vessel. The general appearance of some vessels is shown in Fig. 6, which represents a small portion of a leaf-trace. The phloem-strand ( $p h$.), indicated in the figure, appears discontinuous owing to the irregularity of its course.

Transverse sections of the leaf-trace may present very different appearances at different points in its course through the cortex. In one case, for instance, the petiole has a typical arched bundle, which, on entering the tuber as the leaf-trace, shows rearrangement of its tissues, the xylemelements first changing their course so as to be cut longitudinally in a tangential section of the tuber, thus giving the appearance of a plate of xylem. By a further change of direction there is an almost immediate

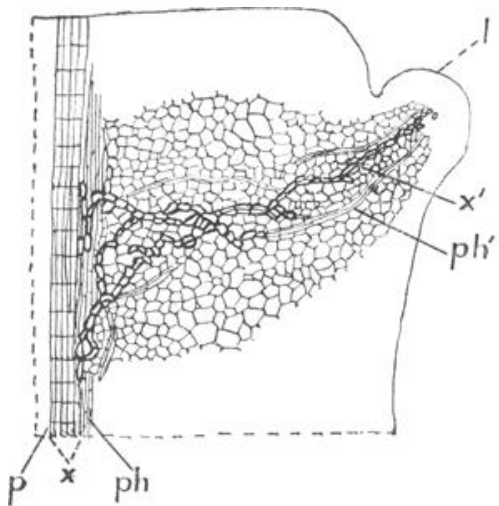

FIG. 5.

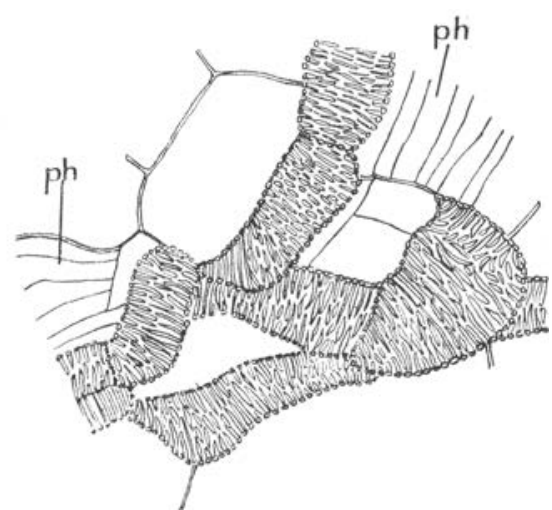

FIG. 6.

FIGs. 5, 6. 5. Longitudinal section of tuber, partly diagrammatic, showing vascular supply of adventitious leaf; $x$. and $p h$. xylem and phloem of stele; $x_{0}{ }^{1}$ and $p h{ }^{1}$, xylem and phloem of leaf-trace; $p .$, pith; $l$., leaf. $x$ about 22.6 . Portion of trace of adventitious leaf cut longitudinally; ph., phloem. $\times 260$.

return to the arched form of bundle, the diameter of the arch being greater than before, and the xylem becoming somewhat interrupted. The trace then, by a slight change, assumes the form of a more or less broken ring of xylem and phloem (ectophloic), and retains this form for some distance, but with irregularities in the course of its tissues. After becoming once more arched, the trace divides into two or three strands preparatory to fusion with the central cylinder. The phloem-strands are sometimes rather widely separated from the xylem.

In one or two cases the petiolar bundle was not arched, but had a small solid cylinder of xylem surrounded by phloem, and this type of structure also was met with in portions of some leaf-traces. Small strands connecting adjoining traces sometimes occur, and, when several leaves are inserted close 
together, their traces may become grouped more or less in a ring. No special morphological significance is attached to the form or course of the leaf-traces.

On examining an adventitious leaf, the lamina of which had its back towards the tuber, it was found that the petiolar bundle was still reversed at the point of attachment of the petiole to the tuber. A partial rotation of the bundle, however, took place at once on entering the tuber.

The leaves referred to so far are those produced on the uninjured surface of the tuber. Other adventitious leaves, however, had been formed on the cut surface of the tuber, but only in a small proportion of the specimens examined. Nothing specially noteworthy was observed in these leaves. Where they occurred near the central region of the cut surface, their vascular traces became attached to the bundles of the stele, not far below the cut ends of the latter, the traces having a very short and nearly vertical course.

Probably a leaf-trace can be formed in the cortex of any part of the tuber, the necessary condition in any given region being that a young leafrudiment should first be formed there.

No definite opinion has been obtained as to the nature of the stimulus requisite for the initiation of the leaf-trace in Cyclamen, but reference may be made to Simon's conclusion regarding somewhat analogous phenomena observed by him in Achyranthes and other plants. ${ }^{1}$ In Simon's experiments a young stem was partially cut across transversely, so that some of the vascular bundles were severed, and observations were made on the development of new bundles, which were formed from parenchymatous tissue in such a manner as to connect the severed bundles above the cut either with uninjured bundles, or with severed bundles below the cut. The development of the new bundles began in parenchyma adjoining the cut ends of bundles above the incision (i. e. in tissue at first somewhat depleted of water ${ }^{2}$ ), and proceeded towards bundles having a direct vascular connexion with the root, and consequently an efficient water-supply. Simon concludes, from the results of his experiments, that there is a stimulus depending on the distribution of water in the tissues, and draws a comparison between the reaction (of bundle development towards the water-supply) and the phenomenon of hydrotropism.

If one supposes the stimulus in Cyclamen to be likewise connected in some way with local scarcity of water, one must assume a degree of depletion of water in the cells adjoining the leaf-rudiment, at an early stage of the latter. This might possibly be due to increased cuticular transpiration

1 Simon: Experimentelle Untersuchungen iiber die Entstehung von Gefässverbindungen. Festschr, deutsch. bot. Gesellsch., I 908, p. 364. See also Küster: Progressus Rei Botanicae, vol. ii, pp. 54I-9; and Freundlich: Entwicklung u. Regeneration von Gefässbündeln in Blattgebilden. Jahrb. f. wiss. Bot., vol. xlvi, I909, p. I37.

2 Owing to interruption of vascular supply of water from below. 


\section{Boodle.-The Mode of Origin and the Vascular Supply of}

of the rejuvenated portion of the epidermis, combined with the transference of water, required for the enlargement of the rudiment and for the production of hairs on its surface.

Goebel, ${ }^{1}$ referring to the production of these adventitious leaves in Cyclamen, states that, as far as is known, they arise directly on the hypocotyledonary tuber, and this certainly appears to be the case, nothing suggesting the preliminary differentiation of an adventitious stem-apex having been observed. Goebel, moreover, regards the production of adventitious leaves as indicating the 'embryonic' nature of the hypocotyledonary region of the seedling.

Certain exogenous buds and roots may be compared with the adventitious leaves of Cyclamen, in that they also require the formation of a vascular connexion across the cortex. In Aristolochia Clematitis adventitious buds are formed on the roots, and according to Beijerinck's description ${ }^{2}$ they show some interesting analogies to the adventitious leaves of Cyclamen. Thus the differentiation of the bud-trace proceeds centripetally through the cortex of the root, and forking of the trace occurs (Beijerinck, Fig. 82). Further, the epidermis of the bud may vary in origin according to the early or late development of the bud, being derived from the outermost layer of the root, or from the next layer beneath. ${ }^{3}$

Beijerinck adds that the chief part of the bud arises from the two or three layers of cells which immediately adjoin the 'epidermis', and may be regarded as cork-meristem.

The formation of exogenous adventitious buds on the hypocotyl has been recorded in species of Linaria, Anagallis, Euphorbia, and other genera. ${ }^{4}$ In these cases the hypocotyl is of normal form, not tuberous as in Cyclamen, and the production of the buds may be spontaneous, but is favoured or increased by the removal of the cotyledons and stem-apex of the seedling, or by encasing these in gypsum, or by the accident of the cotyledons remaining enclosed in the seed-coat. ${ }^{5}$ As adventitious buds do not appear to occur on the epicotyl of these plants, a pronounced formative property may be taken as here characterizing the hypocotyl. The production of adventitious leaves by the tuber of Cyclamen may be classed with the foregoing cases as another example of an active hypocotyl, and

1 Goebel : Einleitung in die Experimentelle Morphologie, 1908, p. 205.

2 Beijerinck : Beobachtungen u. Betrachtungen über Wurzelknospen n. Nebenwurzeln. Natuurk. Verh. Akad. Wetensch. Amsterdam, vol, xxv, p. 10\%.

s Beijerinck, loc. cit.: 'Die dunkelschwarze, Rinde und Knospe überziehende Epidermis wird gewöhnlich durch die Knospe durchbohrt, allein bèi sehr früh angelegten Knospen ist die Epidermis der Mutterrinde ein integrirender Theil der Neubildung.'

4 Goebel: loc. cit.

- Küster : Beobachtungen über Regenerationserscheinungen an Pfanzen. Beih. z. Bot. Centralbl., vol. xiv, 1903, p. 316. Burns and Hedden: Conditions influencing Regeneration of Hypocotyl. Ibid., vol. xix, I906, p. 381 . 
the phenomenon in Cyclamen should probably not be regarded as primarily connected with the tuberous nature of the hypocotyl.

Reference may also be made to the exogenous roots formed in connexion with the axillary buds on the stem of Nasturtium officinale. ${ }^{1}$ Here again vascular strands are developed from cortical tissue, but the tissue concerned is not mature as in Cyclamen, the mode of differentiation of the vascular elements being comparable to that occurring in the development of normal primary vascular tissue.

Among the results obtained, the most interesting are those connected with the origin of the adventitious leaves. The latter, to summarize, may be produced: (I) strictly exogenously, when there is no periderm, or (2) just below the cork, when periderm has been formed, or (3) beneath the cut surface, even from cortical cells. quite near the stele. In the first case the epidermis of the leaf is derived from that of the tuber, while in the second it is subepidermal in origin.

${ }^{1}$ Lemaire: Recherches sur l'origine et le développement des racines latérales. Ann. Sci. Nat., Bot., $7^{\ominus}$ sér., t. iii, p. 237 . 